\title{
A Targeting Sequence Directs DNA Methyltransferase to Sites of DNA Replication in Mammalian Nuclei
}

Heinrich Leonhardt, " Andrea W. Page, ${ }^{*} \dagger$ Heinz-Ulrich Weier, $¥$ and Timothy H. Bestor*

${ }^{\star}$ Department of Anatomy and Cellular Biology

Harvard Medical School

Boston, Massachusetts 02115

$\neq$ Department of Laboratory Medicine

Division of Molecular Cytometry

University of California at San Francisco

San Francisco, California 94143

\section{Summary}

Tissue-specific patterns of methylated deoxycytidine residues in the mammalian genome are preserved by postreplicative methylation of newly synthesized DNA. DNA methyltransferase (MTase) is here shown to associate with replication foci during $S$ phase but to display a diffuse nucleoplasmic distribution in non-S phase cells. Analysis of DNA MTase- $\beta$-galactosidase fusion proteins has shown that association with replication foci is mediated by a novel targeting sequence located near the N-terminus of DNA MTase. This sequence has the properties expected of a targeting sequence in that it is not required for enzymatic activity, prevents proper targeting when deleted, and, when fused to $\beta$-galactosidase, causes the fusion protein to associate with replication foci in a cell cycle-dependent manner.

\section{Introduction}

Eukaryotic DNA replication takes place in discrete replication foci, each of which is a large biochemical machine that contains tens to hundreds of replication forks (Nakamura et al., 1986; Mills et al., 1989). The size and distribution of replication foci changes in an ordered manner during $S$ phase; during early $S$ phase, replication foci are $<1 \mu \mathrm{m}$ in size, numerous, and distributed throughout the nucleus, while in middle $S$ phase most DNA synthesis occurs in larger $\mu \mathrm{m}$-sized structures that often have a striking looped or toroidal appearance. DNA synthesis in late $S$ phase is seen in the looped or toroidal structures and in many small replication foci in close proximity to the nuclear envelope (Nakamura et al., 1986; Nakayasu and Berezney, 1989; Fox et al., 1991; O'Keefe et al., 1992). Specific DNA sequences replicate at characteristic stages of $S$ phase (D'Andrea et al., 1983; Goldman et al., 1984; Hatton et al., 1988), and the morphological changes undergone by replication foci during $S$ phase might reflect changes in the replication machinery involved in the restoration of preexisting chromatin structures and states of transcriptional activity to newly replicated DNA.

Tissue-specific patterns of methylated deoxycytidine

tPresent address: Department of Biology, Massachusetts Institute of Technology, Cambridge, Massachusetts 02139 residues in the vertebrate genome are transmitted by clonal inheritance through the action of a DNA (cytosine 5) methyltransferase (MTase). The only species of DNA MTase detected in mammalian cells is a large protein whose $500 \mathrm{C}$-terminal amino acids bear strong sequence similarities to those bacterial type II restriction MTases that form 5-methylcytosine (Bestor et al., 1988; Posfai et al., 1989; Lauster et al., 1989; Bestor, 1990). A region within the 1000 amino acid $\mathrm{N}$-terminal domain suppresses de novo methylation and contains a novel cysteine-rich region between amino acids 537 and 575 that has been shown to bind zinc ions (Bestor, 1992). Suppression of de novo methylation by the $\mathrm{N}$-terminal domain can account for the preference toward hemimethylated DNA exhibited by DNA MTase (Gruenbaum et al., 1982; Bestor and Ingram, 1983). However, proteolytic removal of the $\sim 350$ amino acids at the extreme amino terminus does not affect the enzymatic activity of DNA MTase (Bestor and Ingram, 1985; Bestor, 1992), and no role has been assigned to this region of the protein.

Partial inactivation of the DNA MTase gene by targeted gene disruption has shown that perturbations of methylation patterns are lethal to mouse embryos and to differentiated cells (Li et al., 1992). Faithful clonal transmission of methylation patterns requires the recognition and methylation of all hemimethylated CpG sites prior to the subsequent $S$ phase and might involve close coordination of replication and methylation. We show here that DNA MTase specifically associates with sites of new DNA synthesis in $\mathrm{S}$ phase nuclei. This association is mediated by a novel targeting sequence located near the $\mathrm{N}$-terminus of DNA MTase. These findings suggest that genomic methylation patterns are accurately transmitted to daughter cells through the coordination of DNA replication and methylation together with the intrinsic preference of DNA MTase for hemimethylated DNA.

\section{Results}

\section{Association of DNA MTase with Replication Foci}

The intracellular distribution of DNA MTase during the cell cycle was determined by immunocytochemistry. Domainspecific polyclonal rabbit antibodies were raised against purified TrpE fusion proteins that contained amino acids 137-635 (pATH52) or 927-1502 (pATH32) of murine DNA MTase. The properties and specificity of these antibodies have been described previously (Li et al., 1992; Bestor, 1992). Log-phase mouse 3 T3 fibroblasts stained with either antibody showed the same staining pattern: $70 \%-$ $80 \%$ of the cells had diffuse nucleoplasmic staining with negatively stained nucleoli, and $20 \%-30 \%$ showed staining of distinct nuclear foci (Figure 1A). Many of these foci could be seen by laser scanning confocal microscopy to be looped or toroidal in shape (Figure 1B), and the centers of the toroidal structures stained brightly with the minor groove-binding dye Hoechst 33258 (Figure 1C). The size of the toroidal structures was estimated to be $1-3 \mu \mathrm{m}$ by 

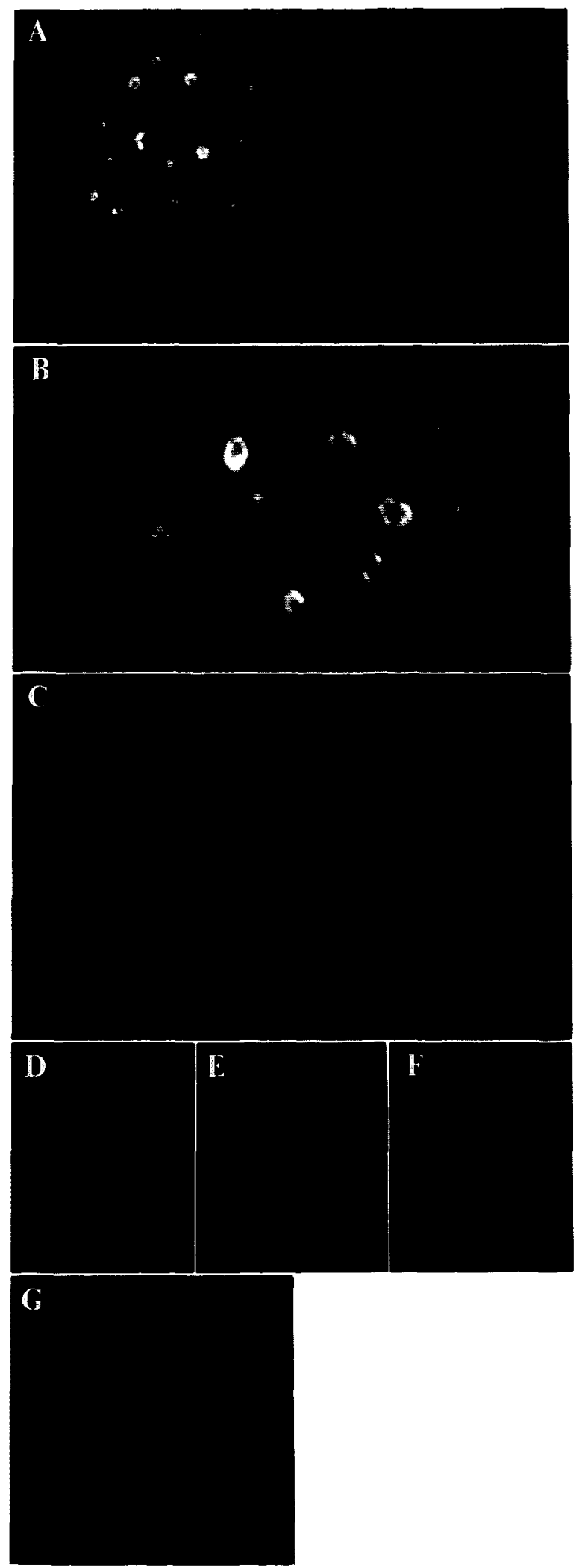

Figure 1. Distribution of DNA MTase in Nuclei of Proliferating $3 T 3$ Fibroblasts

(A) Laser scanning confocal micrograph of cells stained with antibodies to DNA MTase. DNA MTase in the cell at right can be seen to be distributed throughout the nucleoplasm; in the cell at left, DNA MTase comparison with $2 \mu \mathrm{m}$ latex beads added to the mounting medium.

The nature of the looped or toroidal structures was determined by combined immunostaining with anti-pATH52 and fluorescent in situ hybridization. As shown in Figures $1 \mathrm{D}-1 \mathrm{~F}$, in situ hybridization with $\gamma$ satellite probes identified the structures as centromeric heterochromatin (Vissel and Choo, 1989; Weier et al., 1991). Synchronization studies revealed that DNA MTase is present in the looped and toroidal structures during middle to late $S$ phase of the cell cycle (A. W. P. and T. H. B., unpublished data). The Hoechst-stained structures were present throughout the cell cycle (with the exception of M phase), but only during middle and late S phase was DNA MTase seen to concentrate in their vicinity (Figure $1 C$ ). These data suggest an $S$ phase-dependent association of DNA MTase with nuclear structures that are enriched in centromeric heterochromatin.

The structures stained with anti-DNA MTase antibodies in $S$ phase nuclei resembled published micrographs of replication foci in cells pulse labeled with bromodeoxyuridine (BrdU) and stained with anti-BrdU antibodies (Nakamura et al., 1986; Fox et al., 1991; O'Keefe et al., 1992). A method for the simultaneous visualization of protein antigens and BrdU in DNA was developed and used to test for the spatial correspondence of DNA synthesis and DNA MTase localization. 3T3 cells were pulse labeled for 15 min with $10 \mu \mathrm{M} \mathrm{BrdU}$ followed by formaldehyde fixation and staining with anti-pATH52 and rhodamine-conjugated secondary antibodies. Bound antibodies were fixed in place by a second formaldehyde treatment, and incorporated $\mathrm{BrdU}$ was made accessible to antibody by denaturation of DNA with $\mathrm{HCl}$ (see Experimental Procedures). Immunofluorescent staining with monoclonal antibodies to BrdU was used to visualize sites of new DNA synthesis. Figure 2 shows that distributions of DNA MTase and sites of active DNA synthesis are essentially coincident in the nuclei of S phase 3T3 fibroblasts. DNA MTase was seen to be associated with replication foci throughout $S$ phase; a high magnification view of a middle or late $S$ phase nu-

is seen in distinct punctate structures and the nucleoplasm is stained very weakly.

(B) High magnification laser scanning confocal micrograph of a 3T3 cell stained with antibodies to DNA MTase. Notice the looped or toroidal configuration of the structures enriched in DNA MTase.

(C) Conventional immunofluorescence image of 3T3 cells stained by indirect immunofluorescence with antibody to DNA MTase (red) and Hoechst 33258 (blue). DNA MTase can be seen to have a diffuse nucleoplasmic distribution in the cell at left and to have become associated with the structures that stain with Hoechst 33258 in the cell at right.

(D-F) Demonstration by combined immunofluorescence staining and fluorescent in situ hybridization that DNA MTase associates with concentrations of $\gamma$ satellite DNA in nuclei.

(D) DNA stained with DAPI (blue).

(E) DNA MTase visualized by indirect immunofluorescence with fluorescein-conjugated antibody (green).

(F) $\gamma$ Satellite DNA visualized with Texas red-labeled avidin (red) after in situ hybridization with biotinylated $\gamma$ satellite probes.

(G) $3 T 3$ nucleus stained with anti-pATH52 (red) to visualize DNA MTase and with monoclonal antibody $127-3$ (green) to visualize concentrations of splicing factors. 


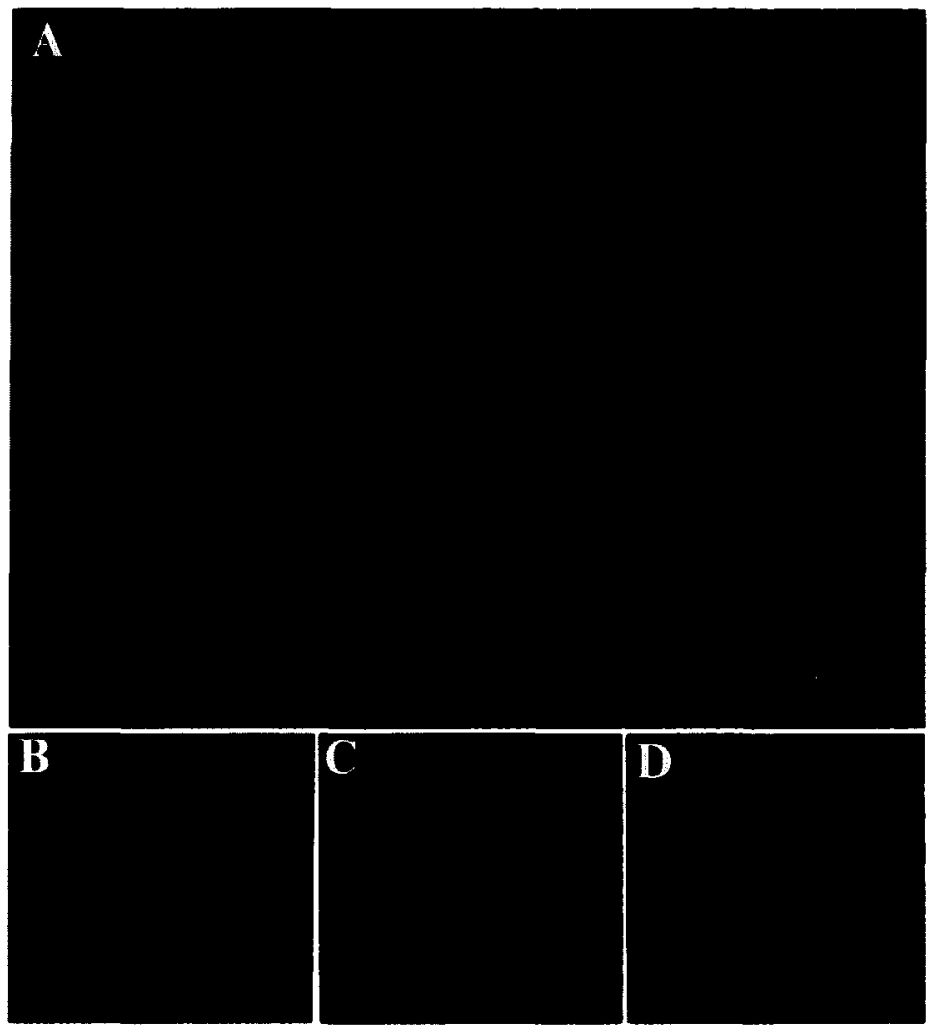

Figure 2. Recruitment of DNA MTase to Sites of Active DNA Synthesis in Nuclei

Log-phase 3T3 cells were pulse labeled with $10 \mu \mathrm{M}$ BrdU for $15 \mathrm{~min}$ and then fixed and stained with antibodies to DNA MTase (red) and BrdU (green).

(A) Survey micrograph. Notice the diffuse nucleoplasmic staining for DNA MTase in cells that have not incorporated $\mathrm{BrdU}$ and the coincident red and green staining (recorded on the film as orange or yellow) due to colocalization of DNA MTase and new DNA synthesis.

(B-D) High magnification views of a single late $S$ phase nucleus.

(B) BrdU incorporation observed with anti-BrdU antibody (green).

(C) DNA MTase visualized by staining with antiPATH52 (red).

(D) Simultaneous visualization of BrdU in DNA and DNA MTase. Coincident staining of replication foci in the nuclear interior is obvious, while small replication foci near the nuclear periphery are reproducibly stained faintly with antibodies to DNA MTase, as seen here. It is not known whether this is significant or an artifact of fixation or staining. cleus is shown in Figures 2B-2D. DNA MTase was also shown to colocalize with the replication protein proliferating cell nuclear antigen, which like DNA MTase has a dispersed nucleoplasmic distribution in non-S phase cells and associates with replication foci in S phase (Bravo and Macdonald-Bravo, 1987; A. W. P. and T. H. B., unpublished data). The distribution of DNA MTase in $S$ phase seemed to resemble that of complexes of splicing factors in nuclei of mammalian cells ( $\mathrm{Fu}$ and Maniatis, 1990; Carmo-Fonseca et al., 1991). However, double-labeled immunofluorescence microscopy with antibodies to splicing factors and DNA MTase showed distinct distributions (see Figure $1 \mathrm{G}$ ). The data presented in this section are most consistent with an $S$ phase-dependent recruitment of nucleoplasmic DNA MTase to replication foci.

\section{A Distinct Peptide Sequence Responsible for Cell Cycle-Dependent Association of DNA MTase with Replication Foci}

The cell cycle-dependent changes in distribution of DNA MTase suggested specific interactions between DNA MTase and one or more factors in replication foci. A series of 18 chimeric DNA MTase-Escherichia coli $\beta$-galactosidase fusion proteins (Figure $3 A$ ) was constructed to test for the presence of a protein domain that could mediate $S$ phase-dependent association of DNA MTase with replication foci. To ensure that each expression construct gave a soluble, stable protein product of the appropriate size, the constructs were introduced into COS1 cells by diethylaminoethyl-dextran-mediated transfection. After $20 \mathrm{hr}$ soluble proteins were extracted and subjected to SDSpolyacrylamide gel electrophoresis followed by immu. noblotting with a monoclonal antibody against $\beta$-galactosidase. As shown in Figure $3 \mathrm{C}$, all 18 constructs produced soluble and stable proteins of the predicted sizes.

The ability of the chimeric proteins to associate with replication foci was evaluated by testing for colocalization with endogenous DNA MTase in transiently transfected 3T3 fibroblasts. Transfected cells were fixed with formaldehyde and stained with anti-pATH32 or anti-pATH52 to localize DNA MTase; chimeric DNA MTase- $\beta$-galactosidase proteins were identified by staining with monoclonal antibodies raised against $\beta$-galactosidase. A construct that encoded amino acids $1-1490$ of DNA MTase and had 630 amino acids of $\beta$-galactosidase fused to the $C$-terminus was found to colocalize with endogenous DNA MTase in replication foci. An internal deletion that removed amino acids 110-307 from this construct caused the chimeric protein to take on a diffuse nucleoplasmic distribution even during $S$ phase. Positive and negative targeting behavior of these two fusion proteins is shown in Figure 3D. DNA MTase was associated with replication foci throughout $S$ phase, but middle and late $S$ phase cells are shown because replication foci are large and well separated at these stages.

The easily discernible targeting behavior of the fusion proteins allowed closer definition of the minimal targeting sequence. C-terminal deletion analysis showed that the targeting sequences were $\mathrm{N}$-terminal of amino acid 455 . $\mathrm{N}$-terminal deletion analysis was complicated by the pres- 
A

DNA MTase amino acids in fusions.

1.1490

$1-109 ; 308-1490$

1-638

1-109; 171-638

$1-109 ; 308-638$

$1-309 ; 386-638$

1-341; 427-638

$1-309 ; 511-638$

$1-511$

$1-455$

1-385

1-310

1-259

$138-511$

$172-511$

207.511

245-511

$301-511$

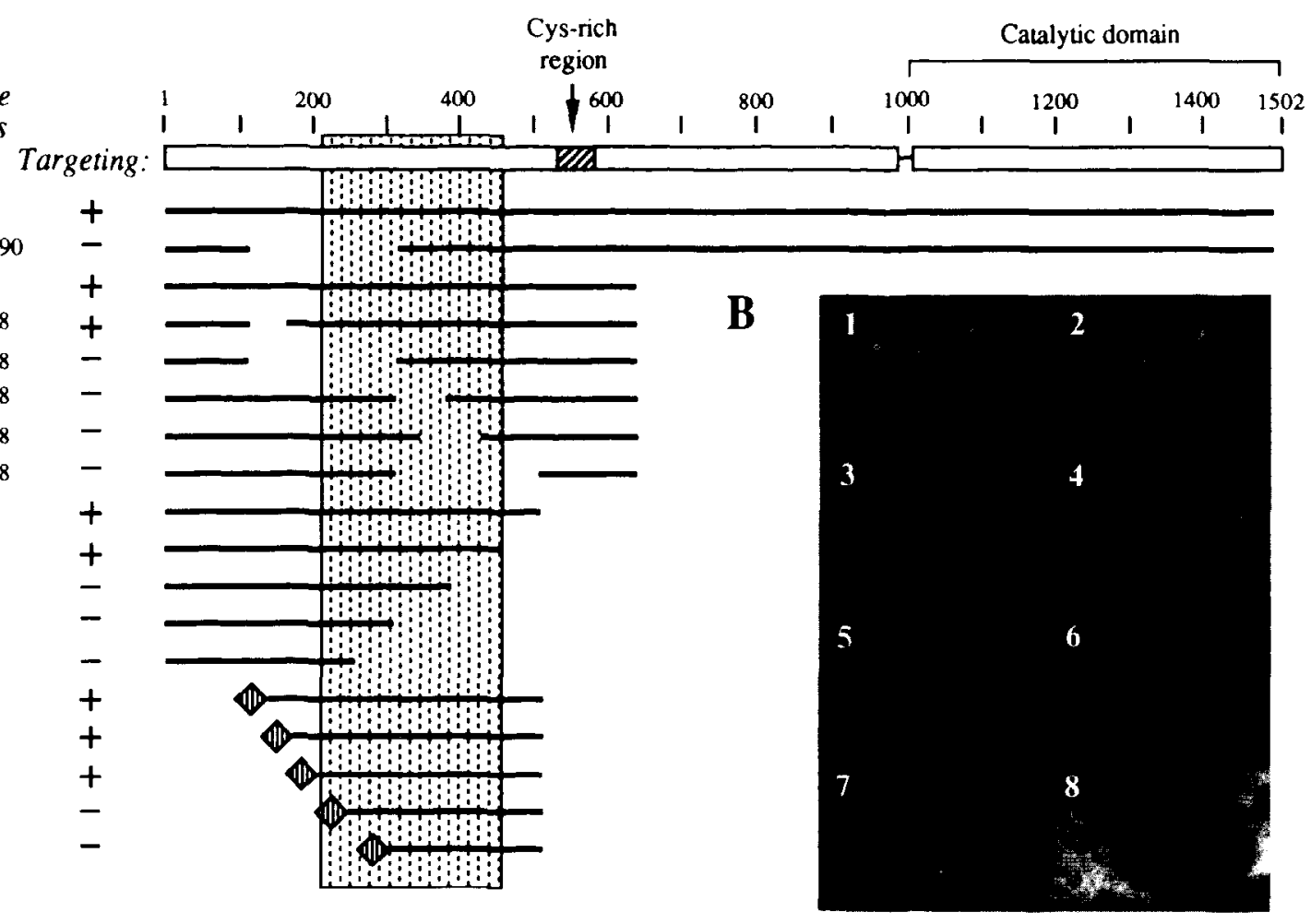

$\begin{array}{ll}\text { C } & 200- \\ \text { ’ } & 116- \\ 9 & 94- \\ \times & 68-\end{array}$

$43-$

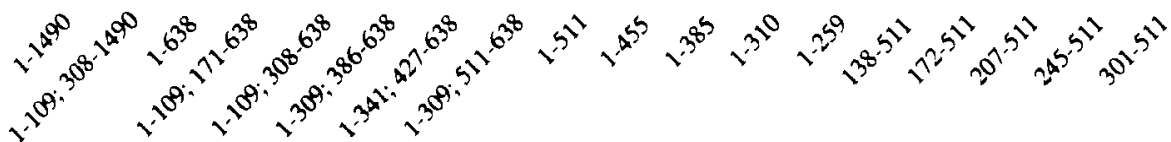

D
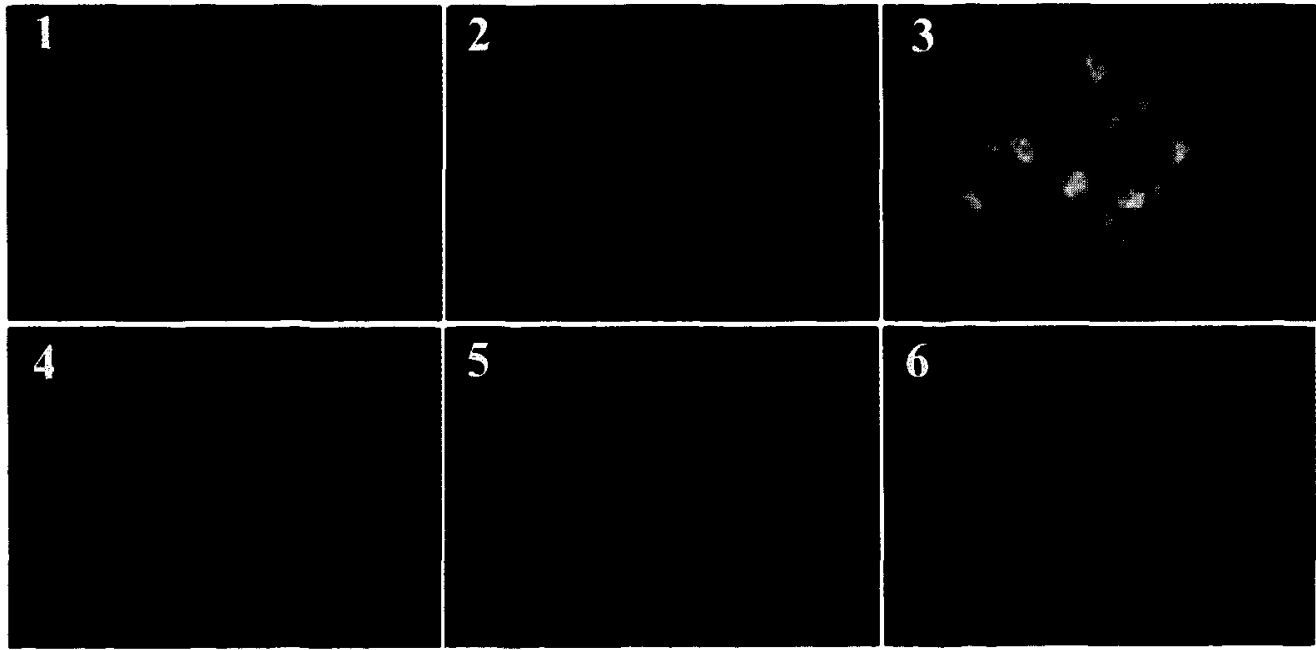

Figure 3. Identification of a Targeting Region near the N-Terminus of DNA MTase

(A) Delineation of the targeting region by deletion analysis. At left are given the amino acids from DNA MTase present in DNA MTase- $\beta$-galactosidase 
ence of a functional nuclear localization sequence between amino acids 72 and 92 whose removal prevented entry of fusion proteins into nuclei (data not shown). Analysis of $\mathrm{N}$-terminal deletion mutants required addition of a synthetic oligonucleotide that encoded the SV40 large T antigen nuclear localization signal to the $5^{\prime}$ end of the coding unit for the chimeric protein (Figure $3 A$; see Experimental Procedures). Analysis of the fusion proteins diagrammed in Figure $3 A$ identified the region between amino acids 207 and 455 as necessary to cause DNA MTase$\beta$-galactosidase fusion proteins to associate with replication complexes in an S phase-dependent fashion indistinguishable from that of endogenous DNA MTase (Figures $3 \mathrm{~A}$ and $3 \mathrm{~B}$ ). It has been shown previously that proteolytic truncation of the first $\sim 350$ amino acids does not affect in vitro enzyme activity (Bestor and Ingram 1985; Bestor, 1992), and deletion of codons 1-307 or 110-307 from the mouse DNA MTase expression construct pEMT (Czank et al., 1991) did not substantially reduce the in vitro enzymatic activity of the product $(\mathrm{H}$. L. and $\mathrm{T}$. H. B., unpublished data). A functional targeting sequence is therefore not required for enzymatic activity.

Alternative explanations for the targeting behavior of DNA MTase were considered. The S phase-dependent association of DNA MTase with replication foci could not be attributed to the high local concentrations of hemimethylated DNA at replication foci since studies of DNA MTase- $\beta$-galactosidase fusion proteins showed that targeting to replication foci is independent of the presence of the C-terminal MTase domain and enzymatic activity (Figure $3 \mathrm{~A}$ ) and is also independent of the region required for the discrimination of unmethylated and hemimethylated DNA (Figure 3A; Bestor, 1992). Furthermore, DNA MTase bearing deletions of part of the targeting region (amino acids 1-307 or 110-307) had full in vitro enzymatic activity when expressed in COS1 cells $(H$. L. and T. H. B., unpublished data). The possibility that targeting is caused by complex formation between the mutant and wild-type DNA MTase endogenous to 3T3 cells and that the sequences responsible for association with replication com- plexes lie elsewhere within the endogenous DNA MTase was excluded on the grounds that targeting of nearly fulllength DNA MTase (which lacked only the last 11 amino acids) fused to $\beta$-galactosidase was abolished only by deletion of sequences within the targeting domain near the $\mathrm{N}$-terminus (Figures $3 \mathrm{~A}$ and $3 \mathrm{D}$ ). Amino acids 207-455 of DNA MTase therefore meet the criteria for a targeting sequence in that deletion of the sequence prevents normal localization of the host protein, fusion to an unrelated protein confers full targeting behavior to the fusion protein, and deletions within the targeting region do not eliminate the enzymatic activity of the affected protein.

\section{Characteristics of the Replication Foci Targeting Region of DNA MTase}

Searches of sequence data bases carried out with the BLASTP algorithm (Altschul et al., 1990) detected two classes of proteins related to DNA MTase. First are the bacterial cytosine $\mathrm{C} 5$ restriction MTases, all of which bear strong similarities to the C-terminal 500 amino acids of DNA MTase (Bestor et al., 1988; Posfai et al., 1989; Lauster et al., 1989). Second are a number of proteins involved in RNA splicing whose similarity to DNA MTase is limited to a region rich in charged and hydrophilic amino acids that is distinct from and immediately $\mathrm{N}$-terminal (amino acids 120-210) of the region that targets DNA MTase to replication foci (207-455). Li and Bingham (1991) found that the serine- and arginine-rich region of the splicing factors encoded by the Drosophila genes suppressor-ofwhite-apricot $\left(s u\left(w^{a}\right)\right)$ and transformer (tra) is capable of conferring to $\beta$-galactosidase the ability to target to complexes of splicing factors in nuclei of COS cells. While concentrations of splicing factors and replication foci appear to be similar in terms of size and number, as shown earlier in Figure 1G, splicing factors and replication foci have nonoverlapping distributions.

The hydrophilicity plot in Figure 4 shows that the replication foci targeting sequence is not located in one of the strongly hydrophilic regions of DNA MTase. The relationship of the replication foci targeting sequence to other

fusion proteins. The relative location of these sequences within DNA MTase is indicated by solid bars drawn to scale. The diamond at the N-terminus of the last five fusion proteins represents a synthetic SV 40 large T nuclear localization signal added to compensate for the deletion of a nuclear localization sequence normally located between amino acids 72 and 92 . The second column from the left reports the targeting behavior of the fusion proteins; examples of positive and negative targeting are shown in (B) and (D). The stippled box denotes the region involved in targeting to replication foci.

(B) Fusion proteins that determine the $\mathrm{N}$ - and $\mathrm{C}$-terminal boundaries of the targeting region. 3 T3 fibroblasts were transfected with constructs 1-455 (1 and 2), 1-385 (3 and 4), 207-511 (5 and 6), and 245-511 (7 and 8). Localization of DNA MTase (stained with anti-pATH52) is shown in the left column, and localization of the fusion proteins within the same cells is shown in the right column (anti- $\beta$-galactosidase staining). Note positive targeting in 2 and 6 and negative targeting in 4 and 8 . Although fusion protein 245-511 (8) was clearly present in the nucleus, for unknown reasons some accumulation in the cytoplasm was also apparent

(C) Demonstration that the DNA MTase- $\beta$-galactosidase fusion proteins are soluble and of the predicted sizes. The fusion constructs shown in (A) were transfected into COS1 cells, and after $20 \mathrm{hr}$ of incubation the cells were extracted with $0.2 \mathrm{M} \mathrm{NaCl}, 0.3 \%$ Triton X-100, $0.3 \mathrm{M}$ sucrose, 20 $\mathrm{mM}$ Tris $-\mathrm{HCl}(\mathrm{pH} 7.4), 3 \mathrm{mM} \mathrm{MgCl}, 0.5 \mathrm{mM}$ dithiothreitol, and $0.2 \mathrm{mM}$ phenylmethylsulfonyl fluoride. The soluble fraction of this mild extract was analyzed by immunoblotting with monoclonal antibody to $\beta$-galactosidase. Numbers at the bottom denote the portion of DNA MTase present in the fusion proteins; the order is the same as in $(A)$.

(D) Elimination of targeting behavior by deletion of sequences near the N-terminus of DNA MTase. $3 T 3$ fibroblasts were transfected with constructs 1-1490 (1-3) and 1-109 and 308-1490 (4-6). DNA MTase was detected with anti-pATH52 and fluorescein-labeled secondary antibodies (1 and 4 ), and fusion proteins were detected with a monoclonal antibody to the $\beta$-galactosidase epitope and rhodamine-labeled secondary antibodies ( 2 and 5). The double exposures demonstrate targeting of fusion protein 1-1490 (3) in clear contrast with the lack of targeting displayed by fusion construct $1-109$ and $308-1490(6)$. 


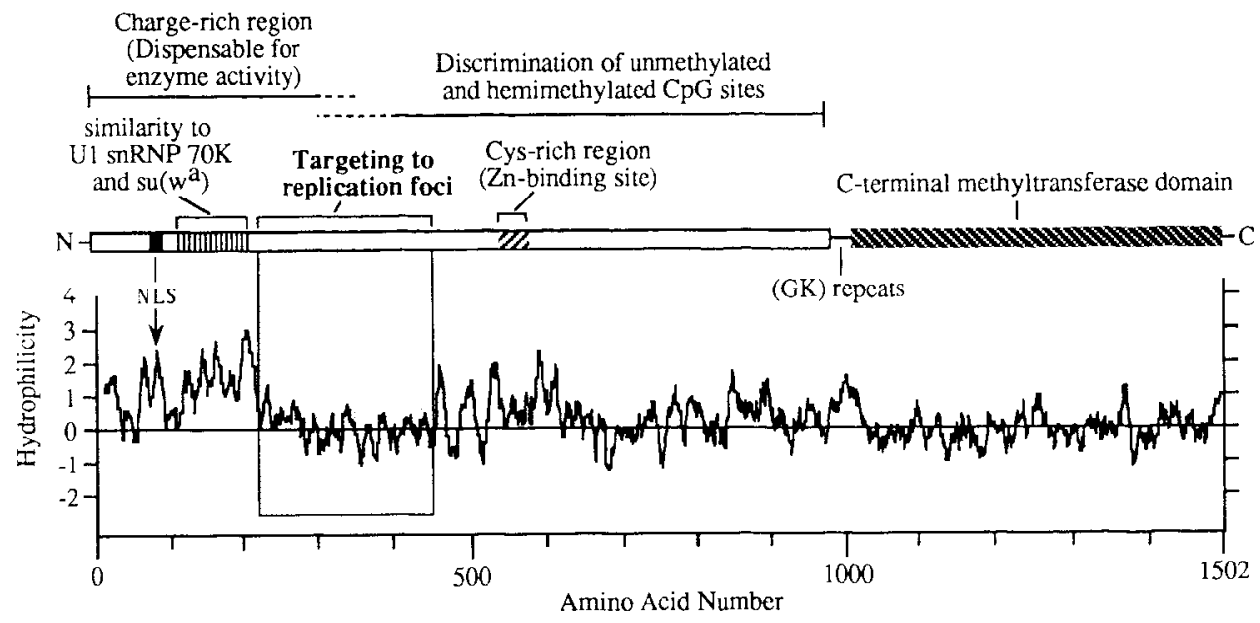

Figure 4. Diagram of Sequence Elements and Functional Domains in Mammalian DNA MTase

The stippled region represents the sequences required for targeting to replication foci during $S$ phase. NLS is a nuclear localization signal located between residues 72 and 92 , and (GK) repeats are the run of alternating lysyl and glycyl residues that join the N-and $\mathrm{C}$-terminal domains of DNA MTase. Notice that hydrophilic sequences have positive values in the hydrophilicity plot.

sequence elements and functional domains in mammalian DNA MTase is shown diagrammatically in Figure 4.

\section{Discussion}

\section{A Novel Targeting Sequence That Controls the Association of DNA MTase with Replication Foci} We have shown here that DNA MTase, the enzyme that ensures the clonal propagation of methylation patterns, has a diffuse nucleoplasmic distribution in $\mathrm{G} 1$ and G2 phases but associates with sites of DNA synthesis throughout $S$ phase. In middle and late $S$ phase, these replication foci are organized around aggregations of centromeric heterochromatin and are observed as striking looped or toroidal structures. It cannot be concluded that these large replication foci are the sites of replication of satellite DNA only, as nonsatellite DNA could be reeled through complexes of replication factors that are affixed to concentrations of centromeric heterochromatin (Cook, 1991).

Analysis of DNA MTase- $\beta$-galactosidase fusion proteins have defined a sequence toward the $\mathrm{N}$-terminus of DNA MTase that is capable of conferring S phase-dependent association of the fusion proteins with replication foci. The replication focus targeting sequence in DNA MTase extends from amino acids 207 to 455 . This region does not contain the very hydrophilic sequences toward the $\mathrm{N}$-terminus or the zinc-binding region between amino acids 537 and 575 and is not significantly related to any protein sequence in the current data bases. However, other classes of targeting sequences often show insufficient sequence similarity to ensure reliable identification by sequence analysis. As many as $20 \%$ of random amino acid sequences can function as targeting signals for the plasma membrane or mitochondrion in yeast (Kaiser et al., 1987; Roise and Schatz, 1988). While most sequences that mediate protein targeting are short (less than 20 amino acids), they can be greater than 100 amino acids in length, as shown for the nuclear localization sequence in the small nuclear ribonucleoprotein U1A (Kambach and Mattaj, 1992) and for the nucleolar localization sequence in the nucleolar protein NO38 (Peculis and Gall, 1992). Association of DNA MTase with replication foci may involve contacts with short peptide sequences that are separated in the primary structure of the targeting region but brought into close proximity in the native folded structure. The hydrophilicity plot of Figure 4 demonstrates that the targeting region is somewhat hydrophobic and might be expected to be folded into the interior region of a globular domain; however, sequences within the targeting region are likely to be exposed on the protein surface, as the region has been shown to contain sites that are accessible to proteases in the native protein (Bestor, 1992).

Several DNA replication enzymes (including DNA MTase) have been reported to cofractionate during purification at low salt concentrations (Tubo and Berezney, 1987; Noguchi et al., 1983; Ottiger and Hübscher, 1984), and immunocytochemistry studies have shown that several proteins involved in DNA replication associate with discrete foci in nuclei of cultured cells; these include DNA polymerase $\alpha$ (Bensch et al., 1982), DNA ligase I (Lasko et al., 1990), and proliferating cell nuclear antigen, a component of the DNA polymerase $\delta$ holoenzyme (Bravo and Macdonald-Bravo, 1987). Assembly of replication foci may involve a web of unique interactions among replication factors or association with an organizing scaffold of structural proteins. In the latter case, it is likely that other components of the replication machinery will be found to contain functional replication foci targeting sequences and that an identifiable consensus sequence might emerge from comparison of these sequences. It is noteworthy that the replication proteins DNA ligase I (Tomkinson et al., 1990) and DNA topoisomerase I (Alsner et al., 1992) are similar to DNA MTase in that they have large regions near 
their $\mathrm{N}$-termini that are protease sensitive and dispensable for enzymatic activity; these $\mathrm{N}$-terminal regions may also contain replication foci targeting sequences comparable in function with that found in DNA MTase.

Searches of the current sequence data bases with the BLASTP algorithm (Altschul et al., 1990) revealed a region near the N-terminus of DNA MTase that is similar in sequence to a region found in a number of eukaryotic splicing factors. The region of similarity is limited to sequences that in the case of the Drosophila splicing factors $s u\left(w^{a}\right)$ and tra have been shown to target those proteins to splicing factor complexes (Li and Bingham, 1991). Double-labeled immunofluorescence showed that DNA MTase does not associate with complexes of splicing factors, and the significance of the sequence similarities between DNA MTase and splicing factors is unclear.

Known replication proteins have long half lives and are present at essentially constant levels in cycling cells (Lasko et al., 1990; Morris and Matthews, 1989). Individual replication proteins may therefore undergo multiple rounds of nuclear import at the conclusion of mitosis and assembly into replication foci in $\mathrm{S}$ phase. At present there is no evidence concerning the nature of the signals that cause the assembly or disassembly of replication foci.

\section{Organization of Mammalian Nuclei}

Nuclei contain numerous distinct compartments or domains that are not separated by membranes. Ribosome assembly (Kumar and Warner, 1972), RNA processing (Wang et al., 1991; Huang and Spector, 1991; Carter et al., 1991; Spector et al., 1991), and DNA replication (Nakamura et al., 1986; Fox et al., 1991; O'Keefe et al., 1992) take place in spatially distinct nuclear compartments, and additional compartments of unknown function have been defined by immunocytochemical staining with autoimmune sera and monoclonal antibodies (Beck, 1961; Ascoli and Maul, 1991; Saunders et al., 1991; Gauthier-Rouvière et al., 1991; Brancolini and Schneider, 1991). Furthermore, transport of macromolecules between nuclear compartments can involve specific intranuclear trackways (Meier and Blobel, 1992; Lawrence et al., 1989). Targeting sequences are likely to be widespread among those nuclear proteins that have restricted nuclear distributions, and experimental overexpression of the targeting domains should inhibit function of the intact endogenous protein by a dominant negative mechanism if assembly into multiprotein complexes is required for the function of the protein. Examination of the stability of methylation patterns in cells overexpressing the targeting region of DNA MTase should give information about the role of coordinated DNA replication and DNA methylation in the inheritance of methylation patterns, and analogous experiments may be of general use in studies of other nuclear proteins.

\section{Experimental Procedures}

\section{Construction of DNA MTase- $\beta$-Galactosidase}

\section{Fusion Constructs}

The mammalian expression vector pEVRFO (Matthias et al., 1989) was used in all plasmid constructs. This vector contains the cytomegalovirus immediate-early enhancer-promoter upstream of the translational start site and first four amino acids of the herpes simplex virus thymidine kinase gene and was designed for the expression of deletion mutants. The deletion mutants shown in Figure 3 were fused at their C-termini to amino acids 361-1069 or 438-1069 of E. coli $\beta$-galactosidase by standard cloning techniques (Sambrook et al., 1989). To allow analysis of $\mathrm{N}$-terminal deletion mutants that had lost the nuclear localization sequence between amino acids 72 and 92 , a synthetic oligonucleotide that encoded the SV40 large T nuclear localization sequence (PKKKRKV) was ligated into the BamHI site in pEVRFO upstream of the DNA MTase- $\beta$-galactosidase fusion construct. Plasmid DNA for transfection was purified by equilibrium centrifugation in $\mathrm{CsCl}$-ethidium bromide gradients.

Cell Culture and Transfection

Swiss $3 T 3$ cells and COS1 cells were grown in Dulbecco's minimal essential medium (DMEM) with $10 \%$ iron-supplemented calf serum (Hyclone) at $37^{\circ} \mathrm{C}$ and $5 \%-6 \% \mathrm{CO}_{2}$. Transfected COS1 cells were used to confirm that stable, soluble fusion proteins of the expected sizes were produced from the plasmid constructs. Cells were grown in $100 \mathrm{~mm}$ dishes to $80 \%-90 \%$ confluence and split 1:6. After 5-10 hr, the cells were washed with phosphate-buffered saline (PBS), incubated for $9 \mathrm{~min}$ with $1 \mathrm{mg} / \mathrm{ml}$ diethylaminoethyl-dextran in PBS, and then washed with PBS. The pretreated cells were incubated with $1 \mathrm{ml}$ of PBS containing $1 \mu \mathrm{g}$ of plasmid DNA for $30 \mathrm{~min}$ at $37^{\circ} \mathrm{C}$. DMEM $(10 \mathrm{ml})$ with $10 \%$ iron-supplemented calf serum and $80 \mu \mathrm{M}$ chloroquine was added, and after $20 \mathrm{hr}$ at $37^{\circ} \mathrm{C}$ cells were scraped from the plates into ice-cold PBS, collected by centrifugation, and extracted with 0.2 $\mathrm{M} \mathrm{NaCl}, 0.32 \mathrm{M}$ sucrose, $0.3 \%$ Triton $\mathrm{X}-100,20 \mathrm{mM}$ Tris- $\mathrm{HCl}(\mathrm{pH} 7.4)$, $3 \mathrm{mM} \mathrm{MgCl}_{2}, 0.5 \mathrm{mM}$ dithiothreitol, and $0.2 \mathrm{mM}$ phenylmethylsulfonyl fluoride. After 5 min centrifugation in an Eppendorf centrifuge at 13,000 $\mathrm{rpm}$ in the cold, the soluble fraction was recovered and used for immunoblot analysis as described (Bestor, 1992). Immunofluorescence analysis showed that transfection rates for COS1 cells were $10 \%$ $20 \%$.

3T 3 cells at $80 \%-90 \%$ confluence were split $1: 10$ and seeded on $22 \times 22 \mathrm{~mm}$ coverslips in DMEM with $10 \%$ iron-supplemented calt serum. After $12-15 \mathrm{hr}$, a plasmid-DOTAP mixture was added in serumfree DMEM as recommended by the vendor of DOTAP (Boehringer Mannheim). After $20 \mathrm{hr}$ the transfection medium was replaced with DMEM plus $10 \%$ iron-supplemented calf serum, and the cells were fixed for immunofluorescent staining after $18 \mathrm{hr}$ incubation.

\section{Immunofluorescence}

Unless specified otherwise, all solutions were prepared in PBS with $1.5 \mathrm{mM} \mathrm{MgCl} 2$ and $1 \mathrm{mM} \mathrm{CaCl}$, and all manipulations were at room temperature. $3 \mathrm{~T} 3$ cells on coverslips were fixed in $3.7 \%$ formaldehyde for $10 \mathrm{~min}$ and permeabilized with $0.2 \%$ Triton $X-100$ for $12 \mathrm{~min}$. Coverslips were incubated for $5 \mathrm{~min}$ in blocking buffer $(5 \%$ goat serum, $0.2 \%$ fish skin gelatin, and $0.2 \%$ Tween 20 ) and then for $45 \mathrm{~min}$ in blocking buffer with primary antibody. $\beta$-Galactosidase fusion proteins were detected with a monoclonal antibody from Promega. Polyclonal rabbit anti-DNA MTase antibodies anti-pATH32 and anti-pATH52 have been described previously (Li et al., 1992; Bestor, 1992). Coverslips were washed with PBS, incubated with second antibody for $30 \mathrm{~min}$, washed three times, and mounted in glycerol containing $50 \mathrm{mg} / \mathrm{mi}$ $n$-propyl gallate. Both anti-pATH32 and anti-pATH52 gave the same staining patterns, and staining patterns were the same whether formaldehyde or methanol-acetone was used as a fixative. Fluorescent second antibodies were obtained from TAGO or Boehringer Mannheim. Hoechst 33258 (Boehringer Mannheim) was used at a final concentration of $5 \mathrm{ng} / \mathrm{ml}$

Simultaneous visualization of DNA MTase and sites of new DNA synthesis involved growth of cells in $10 \mu \mathrm{M}$ BrdU (Sigma Chemical) for 5 or $15 \mathrm{~min}$. Fixation and staining for DNA MTase was as described above; after the final wash, antibodies were fixed in place by treatment with $2 \%$ formaldehyde in PBS for $10 \mathrm{~min}$. After incubation in $50 \mathrm{mM}$ glycine for $10 \mathrm{~min}$, the coverslips were treated with $4 \mathrm{~N} \mathrm{HCl}, 0.1 \%$ Triton X-100 in water for $10 \mathrm{~min}$, washed in PBS and $50 \mathrm{mM}$ glycine, and stained with a monoclonal antibody to BrdU (Becton-Dickinson) and fluorescein-labeled second antibody as described above. Complexes of splicing factors were visualized by staining with monoclonal antibody 127-3 (the gift of Xiang-Dong Fu and Robin Reed). 
Micrographs were taken on Kodak Ektar 100, tktachrome 400, or Tmax 400 with a Nikon Microphot SA or Zeiss Axiophot microscope equipped with $63 \times$ and $100 \times 1.4$ NA planapochromat objectives. Laser scanning confocal micrographs were taken with a Bio-Rad MRC500 instrument mounted on a Zeiss Axiophot microscope.

\section{Combined Fluorescent In Situ Hybridization} and Immunofluorescence

3T3 cells grown on glass slides were fixed and stained with antiPATH52 as described above and then dehydrated with a $70 \%, 90 \%$, and $100 \%$ ethanol series. Cells were overlaid with $20 \mu \mathrm{l}$ of a solution containing $5 U$ of Avall and $65 \mathrm{U}$ of exonuclease III (both from Bethesda Research Laboratories) in $50 \mathrm{mM}$ Tris- $\mathrm{HCl}(\mathrm{pH} 8.0), 10 \mathrm{mM} \mathrm{MgCl}_{2}$, and $50 \mathrm{mM} \mathrm{NaCl}$. After $3 \mathrm{hr}$ at $37^{\circ} \mathrm{C}$, the cells were washed twice in PN buffer $(0.1 \mathrm{M}$ sodium phosphate $[\mathrm{pH} 8.0], 0.1 \% \mathrm{NP}-40)$ at $37^{\circ} \mathrm{C}$ for $10 \mathrm{~min}$ each. Anti-pATH52 was detected with fluorescein-conjugated goat anti-rabbit. The slides were treated with $70 \%$ formamide in $2 \times$ SSC at $72^{\circ} \mathrm{C}$ for $2 \mathrm{~min}$, drained, and incubated overnight at $37^{\circ} \mathrm{C}$ with $30 \mu \mathrm{l}$ of hybridization mixture containing $6 \mu \mathrm{g} / \mathrm{ml}$ of a biotinylated $\gamma$ satellite probe synthesized as described by Weier et al. (1991). After hybridization, the slides were washed once in 50\% formamide, $2 \times$ SSC at $42^{\circ} \mathrm{C}$ and twice in PN at $37^{\circ} \mathrm{C}$, then blocked with PN buffer plus $5 \%$ nonfat dry milk for $5 \mathrm{~min}$, and again incubated with fluoresceinlabeled goat anti-rabbit antibody. After washing twice with PN, hybridized $\gamma$ satellite probe was labeled by incubation with $5 \mu \mathrm{g} / \mathrm{ml}$ Texas red-labeled avidin (Vector Laboratories) in PN plus 5\% nonfat dry milk for $30 \mathrm{~min}$ in the dark. Prior to mounting, the slides were washed twice with PN, and DNA was counterstained with $0.5 \mu \mathrm{g} / \mathrm{ml}$ DAPI (Calbiochem).

\section{Acknowledgments}

The first two authors made equal contributions to this study. We thank Brian Burke, Linda Lou Carlson, J. Richard Chaillet, and Phil Allen for help and advice; Steve Borack and Kent Dayton for photography; Adam Schutz for cell culture; Xiang-Dong $\Gamma u$ and Robin Reed for antibody 127-3; Jeff Yoder and Anthony Forster for criticism of the manuscript; and Biff Morris for advice on confocal microscopy. This research was supported by grant GM43565 from the National Institules of Health (NIH) and grant 5-716 from the March of Dimes Birth Defects Foundation (to T. H. B.), by grant HD17665 from NIH (to H.-U. W.), and by a postdoctoral fellowship from the Deutsche Forschungsgemeinschaft (to H. L.).

The costs of publication of this article were defrayed in part by the payment of page charges. Ihis article must therefore be hereby marked "advertisement" in accordance with 18 USC Section 1734 solely to indicate this fact.

Received August 7, 1992; revised October 8, 1992.

\section{References}

Alsner, J., Svejstrup, J. Q., Kjeldsen, E., Sorenson, B. S., and Westergaard, $0 .(1992)$. Identification of an $\mathrm{N}$-terminal domain of eukaryotic DNA topoisomerase I dispensable for catalytic activity but essential for in vivo function. J. Biol. Chem. 267, 12408-12411.

Altschul, S. F., Gish, W., Miller, W., Myers, E. W., and Lipman, D. J. (1990). Basic local alignment search tool. J. Mol. Biol. 215, 403-410. Ascoli, C. A., and Maul, G. G. (1991). Identification of a novel nuclear domain. J. Cell Biol. 112, 785-795

Beck, J. S. (1961). Variations in the morphological patterns of autoimmune nuclear fluorescence. Lancet 1, 1203-1205.

Bensch, K. G., Tanaka, S., Hu, S.-Z., Wang, T. S.-F., and Korn, D (1982). Intracellular localization of human DNA polymerase $\alpha$ with monoclonal antibodies. J. Biol. Chem. 257, 8391-8396.

Bestor, T. H. (1990). DNA methylation: evolution of a bacterial immune function into a regulator of gene expression and genome structure in higher eukaryotes. Phil. Trans. Roy. Soc. (Lond.) B 326, 179-187.

Bestor, T. H. (1992). Activation of mammalian DNA methyltransferase by cleavage of a $\mathrm{Zn}$-binding regulatory domain. EMBO J. 11, 26112617.

Bestor, T. H., and Ingram, V. M. (1983). Two DNA methyltransferases from murine erythroleukemia cells: purification, sequence specificity, and mode of interaction with DNA. Proc. Natl. Acad. Sci. USA 80, 5559-5563.

Bestor, T. H., and Ingram, V.M. (1985). Growth-dependent expression of multiple species of DNA methyltransferase in murine erythroleukemia cells. Proc. Natl. Acad. Sci. USA 82, 2674-2678.

Bestor, T. H., Laudano, A. P., Mattaliano, R., and Ingram, V. M. (1988). Cloning and sequencing of a cDNA encoding DNA methyltransferase of mouse cells: the carboxyl-terminal domain of the mammatian enzymes is related to bacterial restriction methyltransferases. J. Mol. Biol. 203, 971-983

Brancolini, C., and Schneider, C. (1991). Change in the expression of a nuclear matrix-associated protein is correlated with cellular transformation. Proc. Natl. Acad. Sci. USA 88, 6936-6940.

Bravo, R., and Macdonald-Bravo, H. (1987). Existence of two populations of cyclin/proliferating cell nuclear antigen during the cell cycle: association with DNA replication sites. J. Cell Biol. 105, 1549-1554 Carmo-Fonseca, M., Tollervey, D., Pepperkok, R., Barabino, S. M. L., Merdes, A., Brunner, C., Zamore, P. D., Green, M. R., Hurt, E., and Lamond, A. I. (1991). Mammalian nuclei contain foci which are highly enriched in components of the pre-mRNA splicing machinery. EMBO J. 10, 195-206

Carter, K. C., Taneja, K. L., and Lawrence, J. B. (1991). Discrete nuclear domains of poly(A) RNA and their relationship to the functional organization of the nucleus. J. Cell Biol. 115, 1191-1202.

Cook, P. R. (1991). The nucleoskeleton and the topology of replication. Cell 66, 627-635.

Czank, A., Häuselmann, R., Page, A. W., Leonhardt, H., Bestor, T. H., Schaffner, W., and Hergersberg, M. (1991). Expression in mammalian cells of a cloned gene encoding murine DNA methyltransferase. Gene $109,259-263$.

D'Andrea, A. D., Tantravahi, U., LaLande, M., Perle, M. A., and Latt, S. A. (1983). High resolution analysis of the timing of replication of specific DNA sequences during $S$ phase of mammalian cells. Nucl. Acids Res. 11, 4753-4774.

Fox, M. H., Arndt-Jovin, D. J., Jovin, T. M., Baumann, P. H., and Robert-Nicoud, M. (1991). Spatial and temporal distribution of DNA replication sites localized by immunofluorescence and confocal microscopy in mouse fibroblasts. J. Cell Sci. 99, 247-253.

Fu, X.-D., and Maniatis, T. (1990). Factor required for mammalian spliceosome assembly is localized to discrete regions of the nucleus. Nature $343,437-441$

Gauthier-Rouvière, C., Cavadore, J.-C., Blanchard, J.-M., Lamb, N. J. C., and Fernandez, A. (1991). p67 $7^{\mathrm{SFF}}$ is a constitutive nuclear protein implicated in the modulation of genes required throughout the G1 period. Cell Regul. 2, 575-588.

Goldman, M. A., Holmquist. G. P., Gray, M. C.. Caston. L. A., and Nag. A. (1984). Replication timing of genes and middle repetitive sequences. Science 224, 686-692.

Gruenbaum, Y., Cedar, H., and Racin, A. (1982). Substrate and sequence specificity of a eukaryotic DNA methylase. Nature 295, 620622

Hatton, K. S., Dhar, V., Brown, E. H., lqbal, M. A., Stuart, S., Didamo, V. T., and Schildkraut, C. L. (1988). Replication program of active and inactive multigene families in mammalian cells. Mol. Cell. Biol. 8 , 2149-2158.

Huang, S., and Spector, D. L. (1991). Nascent pre-mRNA transcripts are associated with nuclear regions enriched in splicing factors. Genes Dev. 5, 2288-2302

Kaiser, C. A., Preuss, D., Grisafi, P., and Botstein, D. (1987). Many random sequences functionally replace the secretion signal sequence of yeast invertase. Science 235, 312-317.

Kambach, C., and Mattaj, I. W. (1992). Intracellular distribution of the U1A protein depends on active transport and nuclear binding to U1 snRNA. J. Cell Biol. 118, 11-21.

Kumar, A., and Warner, J. R. (1972). Characterization of ribosomal precursor particles from HeLa cell nucleoli. J. Mol. Biol. 63, 233-246. Lasko, D. D., Tomkinson, A. E., and Lindahl, T. (1990). Biosynthesis 
and intracellular localızation of DNA lıgase I. J. Biol. Chem. 265 , 12618-12622.

Lauster, R., Trautner, T. A., and Noyer-Weidner, M. (1989). Cytosinespecific type II DNA methyltransferases: a conserved enzyme core with variable target-recognizing domains. J. Mol. Biol. 206, 305-312.

Lawrence, J. B., Singer, R. H., and Marselle, L. M. (1989). Highly localized tracks of specific transcripts within interphase nuclei visualized by in situ hybridization. Cell 57, 493-502.

Li, E., Bestor, T. H., and Jaenisch, R. (1992). Targeted mutation of the DNA methyltransferase gene results in embryonic lethality. Cell 69, 915-926

$\mathrm{Li}, \mathrm{H}$., and Bingham, P. M. (1991). Arginine/serine rich domains of the $s u\left(w^{a}\right)$ and tra RNA processing regulators target proteins to a subnuclear compartment implicated in splicing. Cell 67, 335-342.

Matthias, P., Müller, M. M., Schreiber, E., Rusconi, S., and Schaffner, W. (1989). Eukaryotic expression vectors for the analysis of mutant proteins. Nucl. Acids Res. 17, 6418

Meier, U. T., and Blobel, G. (1992). Nopp140 shuttles on tracks between nucleolus and cytoplasm. Cell 70, 127-138.

Mills, A. D., Blow, J. J., White, J. G., Amos, W. B, Wilcock, D., and Laskey, R. A. (1989). Replication occurs at discrete foci spaced throughout nuclei replicating in vitro. J. Cell Sci. 94, 471-477.

Morris, G. F., and Matthews, M. B. (1989). Regulation of proliferating cell nuclear antigen during the cell cycle. J. Biol. Chem. 264, 1385613864

Nakamura, H., Morita, T., and Sato, C. (1986). Structural organization of repticon domains during DNA synthetic phase in the mammalian nucleus. Exp. Cell Res. 165, 291-297.

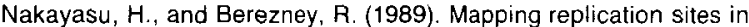
the eukaryotic cell nucleus. J. Cell Biol. 108, 1-11.

Noguchi, H., Prem veer Reddy, G., and Pardee, A. B. (1983). Rapid incorporation of label from ribonucleoside diphosphates into DNA by a cell-free high molecular weight fraction from animal cell nuclei. Cell 32, 443-451.

O'Keefe, R. T., Henderson, S. C., and Spector, D. L. (1992). Dynamic organization of DNA replication in mammalian cell nuclei: spatially and temporally defined replication of chromosome-specific $\alpha$ satellite DNA sequences. J. Cell Biol. 116, 1095-1110

Ottiger, H.-P., and Hübscher, U. (1984). Mammalian DNA polymerase $\alpha$ holoenzymes with possible functions at the leading and lagging strand of the replication fork. Proc. Natl. Acad. Sci. USA 81, 39933997.

Peculis, B. A., and Gall, J. G. (1992). Localization of the nucleolar protein NO38 in amphibian oocytes. J. Cell Biol. 116, 1-14.

Posfai, J., Bhagwat, A. S., Posfai, G., and Roberts, R. J. (1989). Predictive motifs derived from cytosine methyltransferases. Nucl. Acids Res. 17, 2421-2435.

Roise, D., and Schatz, G. (1988). Mitochondrial presequences. J. Biol. Chem. 263, 4509-4511.

Sambrook, J., Fritsch, E., and Maniatis, T. (1989). Molecular Cloning: A Laboratory Manual, Second Edition (Cold Spring Harbor, New York: Cold Spring Harbor Laboratory Press).

Saunders, W. S., Cooke, C. A, and Earnshaw, W. C. (1991). Compartmentalization within the nucleus: discovery of a novel subnuclear region. J. Celi Biol. 115, 919-931.

Spector, D. L., Fu, X.-D., and Maniatis, T. (1991). Associations between distinct pre-mRNA splicing components and the cell nucleus. EMBO J. 10, 3467-3481

Tomkinson, A. E., Lasko, D. D., Daly, G., and Lindahl, T. (1990). Mammalian DNA ligases: catalytic domain and size of DNA ligase I. J. Biol. Chem. 265, 12611-12617

Tubo, R. A., and Berezney, R. (1987). Pre-replicative association of multiple replicative enzyme activities with the nuclear matrix during rat liver regeneration. J. Biol. Chem. 262, 1148-1154.

Vissel, B., and Choo, K. H. (1989). Mouse major $(\gamma)$ satellite DNA is highly conserved and organized into extremely long tandem arrays: implications for recombination between nonhomologous chromosomes. Genomics 5, 407-414.
Wang, J., Cao, L.-G., Wang, Y.-L., and Pederson, T. (1991). Localization of pre-messenger RNA at discrete nuclear sites. Proc. Natl. Acad. Sci. USA 88, 7391-7395.

Weier, H.-U., Zitzelsberger, H. F., and Gray, J. W. (1991). Nonisotopical labeling of murine heterochromatin in situ by hybridization with in vitro synthesized biotinylated gamma (major) satellite DNA Biotechniques 10, 498-505. 